\section{B A Institute of \\ YK Business Administration \\ 六下 \\ Karachi \\ Leadership and Ideas for Tomorrow}

Business Review

Volume 14 Issue 2 July-December 2019

7-1-2019

\title{
Examining the impact of personalization on online advertising engagement: Moderating role of privacy concerns of online users
}

\author{
Uzma Noor \\ International Islamic University, Islamabad, Pakistan \\ Tahira Awan \\ International Islamic University, Islamabad, Pakistan \\ Muhammad Zahid \\ City University of Science and Information Technology, KP Peshawar, Pakistan
}

Follow this and additional works at: https://ir.iba.edu.pk/businessreview

Part of the Finance Commons

\section{(c) (1)}

This work is licensed under a Creative Commons Attribution 4.0 International License.

\section{Recommended Citation}

Noor, U., Awan, T., \& Zahid, M. (2019). Examining the impact of personalization on online advertising engagement: Moderating role of privacy concerns of online users. Business Review, 14(2), 31-46. Retrieved from https://doi.org/10.54784/1990-6587.1016 


\title{
Examining the impact of personalization on online advertising engagement: Moderating role of privacy concerns of online users
}

\author{
Uzma Noor . Tahira Awan . \\ Muhammad Zahid
}

\begin{abstract}
This study examines online advertising engagement as a potential consequence of perceived personalization in online behavioral advertising (OBA) context. Internet users' privacy concerns were analyzed as a moderator on perceived personalization and online advertising engagement relationship. Scenario based activity design was used and 409 usable questionnaires were incorporated in the statistical analysis. The collected data was analyzed using (SPSS) 21 and AMOS 23. Hayes method was used to perform moderation analysis. The moderation analysis showed a significant result but in the opposite direction as hypothesized i.e., high level of privacy concerns made the relationship between perceived personalization and online advertising engagement strong.
\end{abstract}

Keywords Online advertising engagement - Perceived personalization .

Privacy concern.

\section{Introduction}

The fast progress of the internet has helped developing countries to enter the realm of the online world, allowing consumers to communicate and transact all over the world. The e-commerce industry in Pakistan is also developing tremendously (Mustafa et al 2019; Chaudary et al 2014). Each year, its size doubles. Its current value exceeds $\$ 60$ million and its composite growth rate is more than $100 \%$ annually. According to the experts of different industries in the ecommerce zone of Pakistan, the upward growth trend will continue to be on the rise in the future. The e-commerce industry is anticipated to break the $\$ 5$

Uzma Noor

International Islamic University, Islamabad-Pakistan

E-mail: uzma.amer@iiu.edu.pk

Tahira Awan

International Islamic University, Islamabad-Pakistan

Muhammad Zahid

City University of Science and Information Technology, KP Peshawar-Pakistan 
billion mark by 2020. After recognizing the persistence and rapid growth of the commerce industry, many key players of the industry have also started online. Another reason to move online is easier and cheaper internet access for Pakistanis consumers (Nasir, 2016).

A report titled "2018 Connected Commerce" by Nielsen found that $82 \%$ of consumers with internet access in urban areas of Pakistan had made an online purchase, an increase of $6 \%$ over 2017. The growth in e-commerce in recent years is ascribed to the rise in the use of the internet and smartphones. There is a contribution of the urban area of the country to the online sales of different categories of consumer products, as disclosed by the report. Fashion accounts for the largest share of online transactions with $40 \%$, followed by travel with $31 \%$ and IT with $29 \%$. The report describes consumers' online shopping habits and discloses categories that have experienced significant growth in e-commerce activity, including restaurants offerings as $24 \%$, personal care and beauty products as $22 \%$, music and books as $28 \%$ (Farooq, 2018). Such progress gives opportunity to online retailers to take advantage by communicating with their current customers and prospects via online advertising.

Although online advertising revenues have increased, their contribution is negligible from display advertising (IAB, 2017). Despite having an encouraging future of online advertising, online users mostly avoid displaying online advertising (Cho 2004). Over time, online display advertising has dropped significantly in their click through rates. Compared to the click rate in 1994 as 44\% (Robinson et al 2007; Wasserman 2013), the current average click rate is not even $1 \%$ (Tucker 2014). Among the different display formats, online behavioral advertising (OBA) has proven to be a better alternative (Bleier and Eisenbeiss 2015b). Online behavioral advertising is the one that is sent to the internet users on the basis of their behavior and recent history of browsing (Boerman et al 2017). It is based on the personalization strategy. Personalization in the perspective of OBA can be defined as "sending a relevant message to the right consumers at the right time to help them achieve their objectives" (Tam and Ho 2006). The message is perceived as personalized by online users if it is judged by them as close to their preferences ( $\mathrm{Li} 2016)$.

The results of personalization are unclear in academic research (Kim and Huh 2017). Some researchers have reported a favorable response (Van Doorn et al 2010; White et al 2008) of consumers, while some have reported an unfavorable response (Van Doorn et al 2010; White et al 2008; Tucker 2014). Considering that the previous studies on the effects of personalization are indecisive and inconsistent, it is necessary to further investigate the moderators in the relationships already explored. In addition, given that there is a difference between actual and perceived personalization (Li 2016), this study aims to quantify the concept of perceived personalization and its effects on online advertising engagement. Since the effect of personalization is not as simple (Aguirre et al 2015; Bleier and Eisenbeiss 2015b), its study in Pakistani circumstances can help advertisers improve strategies for online consumers in developing countries. This study therefore aims to examine it in the perspective of Pakistan to certify paramount management practices in developing countries.

The engagement has been extensively used in a variety of disciplines, but is 
comparatively little taken into account in the online advertising literature (Kim et al 2017). Online advertising is about engaging the customer with a brand, its message and its environment (Rappaport 2007; Wang 2006). It is important to investigate its role for a couple of reasons. Firstly, engagement is the emotional bond consumers have with a brand or organization (Rappaport 2007) that helps them develop brand-friendly intentions and behaviors (Kim et al 2017; Wang 2006). Secondly, the main objective of advertisers is to involve and immerse consumers in their offers (Hollebeek 2011). Thus, it is important to inquire the contribution of perceived personalization on online advertising engagement.

Although the literature shows a better click rate on online behavioral advertising comparative to generic online advertising (Bleier and Eisenbeiss 2015b; Tucker 2014; Sherman and Deighton 2001), but, researchers have empirically proven reasons why online behavioral advertising was often avoided by online users. The most reoccurring reason for avoiding OBA mentioned in the academic literature is the confidentiality issue that is often attributed to the integral characteristic of personalization in OBA (Aguirre et al 2015; Bleier and Eisenbeiss 2015b; Tucker 2014; Baek and Morimoto 2012). The varied findings in literature about personalization's effect (Van Doorn et al 2010; White et al 2008; Tucker 2014) can be credited to online privacy concerns. How online users' privacy concerns effect the perceived personalization and online advertising engagement relationship is the next line of investigation.

In adopting Westin (1967) privacy terminology, perceived privacy concerns are defined as the degree of consumer concern regarding a possible infringement of the right to prevent privacy, and the release of personal information to third parties. Wherever it is about personalization, the loss of personal data and consumer privacy concerns are often mentioned as the most significant concern of online consumers (Lee et al 2015; Van Noort et al 2013; Ur et al 2012; Turow et al 2009). Much work with respect to personalization effects and privacy concerns has been investigated in western culture (Lee et al 2015; Van Noort et al 2013; Ur et al 2012; Turow et al 2009). Considering the utmost importance of privacy concerns when it comes to personalization effects, the present study empirically examines the effect of Pakistani internet users' apprehensions on the protection of their internet privacy.

The stimulus organism response model (SOR) provides support to the theoretical framework of this research. The SOR model suggests that after being exposed to the influence of stimuli, the receiver first processes the information (Organism), then makes a decision on how to give response (Jacoby 2002)(Mehrabian \& Russell, 1974). The research focuses on the causal link between the predictor variable (perceived personalization) and the outcome variable (online advertising engagement). The study also intends to evaluate the potential moderating effect of online privacy concerns on the said relationship. 


\section{Literature review}

2.1 Effect of perceived personalization on online advertising engagement

With respect to SOR model (Jacoby 2002), when an online user encounters an OBA stimulus, they cognitively treat it and may identify personalization upto a certain level, ultimately, may respond by forming advertising engagement. Engagement is a positive attitude resulting from communication about a brand or product (Advertising Research Foundation, 2006).

Marketers personalize the OBA to suit the interests of users. Personalization in OBA increases with the ad's increasing relevance based on demographics, interest, and the web-user's previous behavior of surfing (Boerman et al 2017). The more personalized the advertisement, the more relevant it is. Celsi and Olson (1988) explained relevance as the degree up to which a receiver recognizes an entity as being self-binding and useful in attaining aims and values. The goal is to offer users with the right message at the right stage to help them make the right choices (Tam and Ho 2006). Thus, the user must make fewer cognitive efforts to process the information (Wilson \& Sperber, 2004). The relevancy of the message translates into a positive attitude towards a brand or product (Kim and Huh 2017; Pavlou and Stewart 2000).

Perceived personalization is the view of the recipient whether the advertisement is relevant to their interests and/or purposes (Li 2016). Advertising that matches user interests and online behaviors is seen as beneficial and valuable (Baek and Morimoto 2012). For example, online users are more likely to treat them cognitively and consider them more engagable (Kim and Huh 2017; Calder et al 2009; Wang 2006; Kim et al 2017). Because of its relevance to consumer behavior and interests, OBA receives a positive consumer reaction (Baek and Morimoto 2012; Bleier and Eisenbeiss 2015b; Kim and Huh 2017). A user's general interest in a product category or type is usually the basis of his/her engagement with the product (Vivek et al 2009). Thus, a message in advertising will have more effectiveness because it is both related and available to the consumer (Baker and Lutz 2000). The OBA is based on personalization strategy, so it is related to the interest and behavior of consumers (Kim and Huh 2017). As a result, the perceived personalization because of OBA will turn into an online advertising engagement. Thus, the following hypothesis is developed.

H1: Perceived personalization positively and significantly affects online advertising engagement.

\subsection{Privacy concerns as a moderator}

Conscious consumers want to control their information to some extent, which is the case for the majority of consumers (Phelps et al 2000). As OBA is sent to online users based on their past information, behavior, and interests (Boerman et al 2017), the causal relationship between perceived personalization and online advertising engagement may be affected because of privacy issues. The personalization effect may be considered as an invasion of privacy by some users 
Impact of personalization on online advertising engagement...

(Stanaland et al 2011). Highly personalized advertising generates strong irritation, increased skepticism about the personalized advertisements and increased online consumer concern over their privacy (Aguirre et al 2015; Baek and Morimoto 2012; Bleier and Eisenbeiss 2015b; Tucker 2014). This may direct them to think about their personal information being at risk, and that marketers and/or third parties are following them (Baek and Morimoto 2012).

Goldfarb and Tucker (2011) believe that privacy issues can decrease the effectiveness of advertising. Their results indicated that the advertisements that present a close match to the website's content are annoying, decreasing the purchase intent. This failure seems to be related to privacy concerns: the adverse effect of the combination of targeting and intrusion is stronger for those who refuse to use their income and for those categories where the protection of privacy matters the most. Likewise, it is also argued by Baek and Morimoto (2012) that personalized advertising raises users' concerns. Consistent with former results (Dolnicar and Jordaan 2007; Nowak and Phelps 1992; Sheehan and Hoy 1999), their study also confirmed that privacy concerns may adversely affect consumers' perception of advertising practices and behavioral intentions.

Kim and Huh (2017) concentrated on the role of perceived relevance and privacy as key factors inducing users' attentions, attitudes and behavioral responses to online behavioral advertising. The conclusion revealed that consumers were very alarmed about privacy hazards related to the collection and exploitation of their personal data. Although respondents did not perceive OBA as predominantly relevant, it was a very robust predictor of consumer response to OBA. Based on the discussion above, it can be reasoned that privacy concerns of online users may affect the bond between perceived personalization and advertising engagement. So, it is hypothesized that,

H2: Privacy concerns moderate the relationship between perceived personalization and online advertising engagement in such a way that the relationship will be weaker if the privacy concerns of online users are high.

Conceptual Framework

Stimulus

Organism

Response

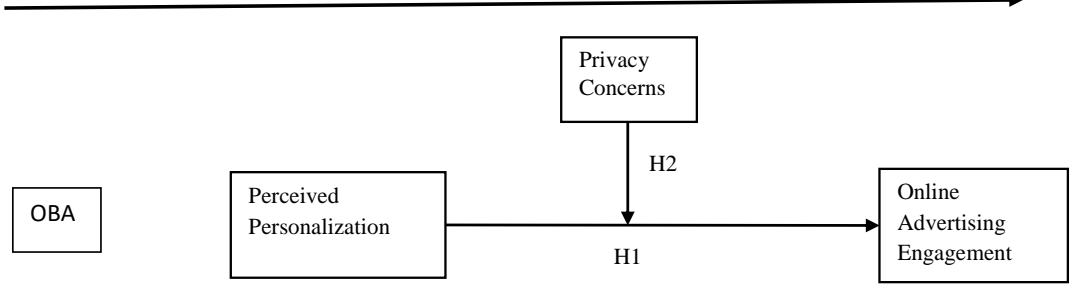

Fig. 1: Proposed model 


\section{Methodology}

Respondents directed a scenario-based activity to quantify the influence of online behavioral advertisement on the perception and attitude of online users. OBA was used to study the cause and effect relationship between study variables. Data was obtained using a structured questionnaire for each and every variable in the study. Using a five-point likert scale $(1=$ strongly disagree to 5 $=$ strongly agree), three variables were quantified in this study. Four items scale of perceived personalization was derived from Dijkstra (2004). This scale is also used by Aguirre et al (2015). Four points scale of Kim et al (2017) has been used to measure the online advertising engagement. Respondents responded to privacy concerns on the four point scale established by Smith et al (1996). Few elements included in the current study were adapted to suit the required perspective.

The population of the study consists of internet users from Rawalpindi and Islamabad. The size of the internet user population in Islamabad / Rawalpindi is not available in exact figures. Thus, no sampling frame was available. Therefore, convenience sampling was used. An online calculator is used to determine the sample size (http://www.calculator.net/sample-size-calculator.html). An appropriate sample size as per the formula is 385 (Krejcie and Morgan 1970). With 409 complete responses, the response rate was $68 \%$. Demographics of participants are displayed in table 1.

\subsection{Data collection procedure}

The eligibility of the respondents for the study was based on the screening questions. The questions were; (1) Do you use the internet? (2) List down the names of the most reoccurring online retailers for which you are purchasing online? To avoid the commitment already developed, only participants who did not buy anything online from the selected retailer for this study were selected. Respondents signed in with their new user IDs developed by them on the first day and also logged in with that ID for the experience the following day. The reason for selecting cell phone as a product displayed in OBA is that, regardless of their age, users are informed about this product (Cui et al 2010). The activity was carried out in a natural setting as an actual online retailer and its advertisement was included (Bleier and Eisenbeiss 2015a). This has not only contributed to amassing the internal validity of the experience (Bleier and Eisenbeiss 2015a), but also contributed to external validity (Calder et al 2009).

To avoid the effect of degradation, a scenario-based activity was conducted for two successive days (Berman et al 2009). Daraz.pk was selected for this study. It is one of the most dependable online stores in Pakistan (Christian, 2017). Selected respondents were given a scenario on the first day. They completed the activity stated in the scenario in the computer lab. Respondents completed the questionnaire on the second day after the end of the activity. 
Impact of personalization on online advertising engagement...

Table 1: Demographics (N=409)

\begin{tabular}{|c|c|c|c|}
\hline \multicolumn{2}{|l|}{ Demographics } & \multirow{2}{*}{$\frac{\text { Frequency }}{218}$} & \multirow{3}{*}{$\begin{array}{c}\% \text { of total } \\
53 \\
47\end{array}$} \\
\hline Gender & Male & & \\
\hline & Female & 191 & \\
\hline \multirow[t]{5}{*}{ Age } & Less than 20 & 56 & 13 \\
\hline & 21-30 years & 187 & 46 \\
\hline & $31-40$ years & 69 & 17 \\
\hline & $41-50$ years & 65 & 16 \\
\hline & $>50$ & 32 & 8 \\
\hline \multirow[t]{2}{*}{ Marital status } & Married & 120 & 29 \\
\hline & Unmarried & 289 & 71 \\
\hline \multirow[t]{6}{*}{ Income } & ¡ 20,000 & 208 & 51 \\
\hline & $21,000-40,000$ & 94 & 23 \\
\hline & $41,000-60,000$ & 34 & 8 \\
\hline & $61,000-80,000$ & 21 & 5 \\
\hline & $81,000-100,000$ & 16 & 4 \\
\hline & $>100,000$ & 36 & 9 \\
\hline \multirow[t]{5}{*}{ Education } & Intermediate & 12 & 3 \\
\hline & Bachelor & 129 & 32 \\
\hline & Master & 202 & 49 \\
\hline & MPhil & 62 & 15 \\
\hline & $\mathrm{PhD}$ & 4 & 1 \\
\hline \multirow[t]{5}{*}{ Occupation } & Students & 165 & 40 \\
\hline & Self employed & 37 & 9 \\
\hline & Private job & 139 & 34 \\
\hline & Government job & 47 & 11 \\
\hline & Others & 21 & 5 \\
\hline
\end{tabular}

\subsection{Scenario}

The following scenario was read by the respondents.

"Suppose you have decided to replace your mobile phone. For this purpose, you would search on Google and from different options available; you would go to a website (Daraz.pk). You would inquire about a mobile phone and leave the website."

\subsection{Activity}

The next day, the respondents received computers in a laboratory. They were asked to use their ID developed for the activity assigned to them and to use the internet for up to 10 minutes ( $\mathrm{Li}$ et al 2002). The researchers removed those respondents from the analysis who devoted less than six minutes to fulfill the assigned task following Bleier and Eisenbeiss (2015a). As per Aguirre et al (2015), an attention check was performed. Participants were required to reply to an open-ended question about the website displaying the OBA.

While the respondents were busy performing their online task, the personalized advertisement from Daraz.pk, showing the same product as inquired by 
the respondents on the previous day sprung up as a usual practice of online advertisers to direct such advertisement to online users.

\section{Results}

SPSS 21 and AMOS 23 were used to examine the data and run the analysis. The reliability and the validity of the scales were tested before running the measurement model. A confirmatory factor analysis was executed to quantify the convergent and discriminant validities of the variables.

The confirmatory factor analysis of this study includes three factors: perceived personalization, online advertising engagement, and privacy concerns. The outcome shows a good fit of the model (table 2) with values in suitable ranges $(\mathrm{CMIN} / \mathrm{DF}=2.02, \mathrm{CFI}=0.97, \mathrm{RMESA}=0.05)$. The statistically significant factor loading $(>0.05)$ shows the convergent validity (as shown in fig.2) (Hair et al 1998). The values of correlation between the variables support

Table 2: Model fit

\begin{tabular}{lccccc}
\hline Measurement model & CMIN/DF & CFI & GFI & AGFI & RMESA \\
\hline 4 Factor Model & 2.02 & 0.97 & 0.96 & 0.94 & 0.05 \\
Acceptable Range & $<3$ good; & $>0.95$ great & $>0.95$ great & $>0.80$ great & $<0.05$ good; \\
& & & & & $0.05-0.10$ \\
& & & & & moderate \\
\hline
\end{tabular}

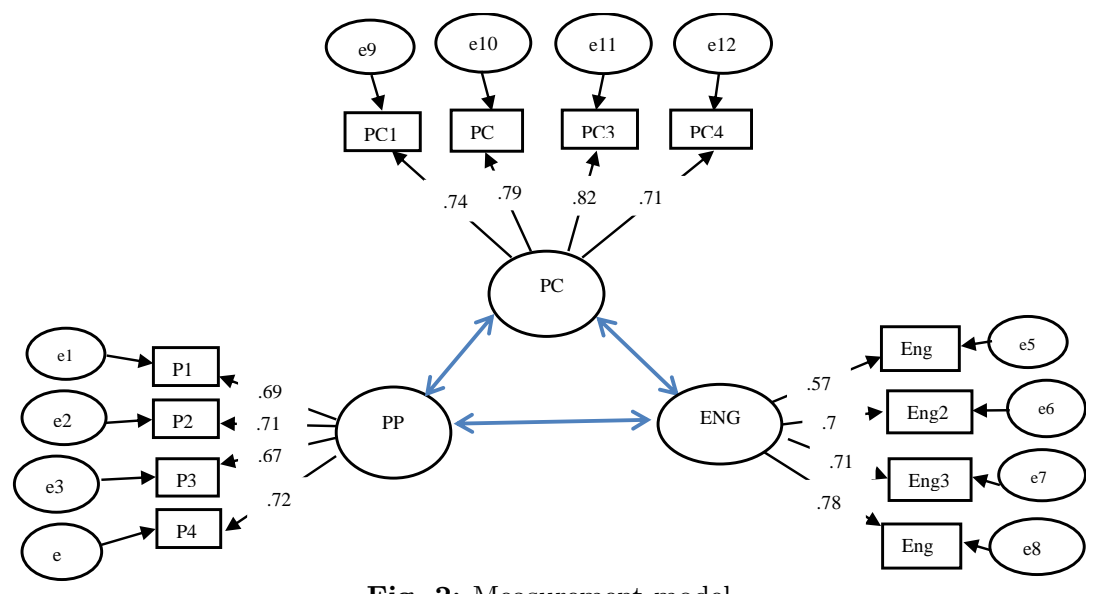

Fig. 2: Measurement model

the hypothesis with the exception of the moderator. The correlation between the moderator, the independent variables and the dependent variables is insignificant (-0.36). The Cronbach Alpha reliability of all the three variables is greater than 0.70 (Hair et al 1998). This indicates the internal dependability of all constructs. The values of the mean and standard deviation indicate that the 
data is prone to agreement. The normality of the data is also indicated by the values of Skewness and Kurtosis is in the range -1 to +1 . VIF $(<10)$ statistics and tolerance level $(>0.01)$ indicate linear collinearity.

Table 3: Correlation, reliability, normality, descriptive and collinearity statistic $(\mathrm{N}=409)$

\begin{tabular}{lcccc}
\hline Construct & PP & ENG & ITC & PC \\
\hline PP & $1(0.790)$ & & & \\
ENG & $.309^{* *}$ & $1(0.790)$ & & \\
ITC & $.329^{* *}$ & $.419^{* *}$ & $1(1$-item $)$ & \\
PC & 0.900 & -0.036 & 0.630 & $1(0.85)$ \\
\hline Skewness & -0.32 & -1.01 & -0.57 & -0.05 \\
Kurtosis & -0.06 & 1.76 & -0.02 & 0.03 \\
Mean & 3.50 & 3.50 & 3.40 & 3.70 \\
St. Deviation & 0.69 & 0.69 & 0.94 & 0.82 \\
Tolerance & 0.89 & 0.82 & 0.81 & 0.98 \\
VIF & 1.13 & 1.22 & 1.22 & 1.01 \\
\hline
\end{tabular}

Note. $\mathrm{PP}=$ Perceived personalization, $\mathrm{ENG}=$ Online advertising engagement, $\mathrm{PC}=$ Privacy concerns, $\mathrm{ITC}=$ Intention to click. ${ }^{* *} . \mathrm{p}<0.01$

\subsection{Hypotheses testing}

\subsubsection{Linear regression}

Simple linear regression analysis was used to measure the direct effect of perceived personalization on online advertising engagement (table 6 ). The variation $\mathrm{R} 2$ in online advertising engagement is $0.33 \%$ due to perceived personalization. A one unit increase in perceived personalization will result in an increase of 0.306 units of online advertising engagement $(\beta=0.306, \mathrm{p}<0.001)$. Therefore we accept $\mathrm{H} 1$.

Table 4: Effect of perceived personalization on online advertising engagement

\begin{tabular}{lcccccc}
\hline Variable & $\beta$ & S.E. & $\beta$ & t & R2 & F \\
\hline Constant & 2.280 & 0.239 & & 9.530 & & \\
Perceived Personalization & 0.302 & 0.047 & 0.306 & 6.500 & 0.329 & 42.240 \\
\hline DV=ENG & & & & & &
\end{tabular}

\subsection{Moderation analysis}

In accordance with Hypothesis 2, online privacy concerns moderate the relationship so that the interactive influence of perceived personalization and privacy

Business Review: (2019) 14(2):31-46 


\section{U. Noor et al}

concerns weakens the relationship between perceived personalization and online advertising engagement if privacy concerns are high. The result of Process Model 1, using 10,000 bootstrap samples and a 95\% confidence interval, revealed that the combined outcome of personalization and privacy concern is significant $(\mathrm{LLCI}=0.0312, \mathrm{ULCI}=0.249)$. Moderating effect of privacy concern decreases from high $(\beta=0.430, \mathrm{p}<0.05)$ to medium $(\beta=0.316, \mathrm{p}<0.05)$ to low $(\beta=$ $0.201, \mathrm{p}<0.05)$. The increase in the size of the effect (beta) shows that the relationship between perceived personalization and online advertising engagement is being strengthened with increasing concerns about online user privacy. Therefore, Hypothesis 2 is not supported. It also appears via the moderation graph

Table 5: Conditional effect of privacy concerns between perceived personalization and online advertising engagement $(\mathrm{N}=409)$

\begin{tabular}{|c|c|c|c|c|c|c|c|c|c|}
\hline Parameters & Dependent & $\mathrm{R} 2$ & $\mathrm{~F}$ & $\mathrm{P}$ & Coef & SE & $\mathrm{t}$ & LLCI & ULCI \\
\hline Constant & & & & & 3.340 & 0.180 & 18.360 & 2.990 & 3.700 \\
\hline $\mathrm{PP}$ & & & & & 0.316 & 0.050 & 6.780 & 0.220 & 0.410 \\
\hline & ENG & 0.352 & 9.440 & 0.000 & & & & & \\
\hline $\mathrm{PC}$ & & & & & -0.024 & 0.041 & -0.583 & -0.104 & 0.057 \\
\hline $\mathrm{PP}^{*} \mathrm{PC}$ & & & & & 0.140 & 0.055 & 2.531 & 0.031 & 0.249 \\
\hline \multicolumn{10}{|c|}{ Conditional effect from $\mathrm{X}$ to $\mathrm{Y}$ at values of moderator } \\
\hline & & $\mathrm{PC}$ & Effect & $\mathrm{SE}$ & $\mathrm{t}$ & LLCI & ULCI & & \\
\hline & & -0.819 & 0.201 & 0.062 & 3.240 & 0.079 & 0.324 & & \\
\hline & & 0.000 & 0.316 & 0.047 & 6.780 & 0.224 & 0.408 & & \\
\hline & & 0.819 & 0.430 & 0.068 & 6.370 & 0.298 & 0.563 & & \\
\hline
\end{tabular}

Note. Controls= Marital status, Income, Occupation

that the link between perceived personalization and online advertising engagement weakens when the privacy concerns is low. As personalization increases, online advertising engagement decreases for online users with low privacy concerns. On the other hand, online users with high privacy concerns reinforce the relationship between $\mathrm{X}$ and $\mathrm{Y}$. Results of moderation led the researchers to further probe into the level of the privacy concerns in different age brackets. The mean values of privacy concerns were calculated for each age bracket of the respondents. Results showed the increasing mean values as respondents' age increases. The results of moderation have led researchers to investigate the level of privacy concerns among multiple age groups. The average values of privacy concern calculated for each age group of respondents reveal that average values increased with the age of respondents.

Table 6: Mean values of privacy concerns in different age brackets

\begin{tabular}{lc}
\hline Age & Mean (Privacy concerns) \\
\hline Less than 20 & 3.3 \\
21 to 30 & 3.6 \\
31 to 40 & 3.7 \\
41 to 50 & 3.8 \\
51 and more & 4.0 \\
\hline
\end{tabular}

40 
Impact of personalization on online advertising engagement...

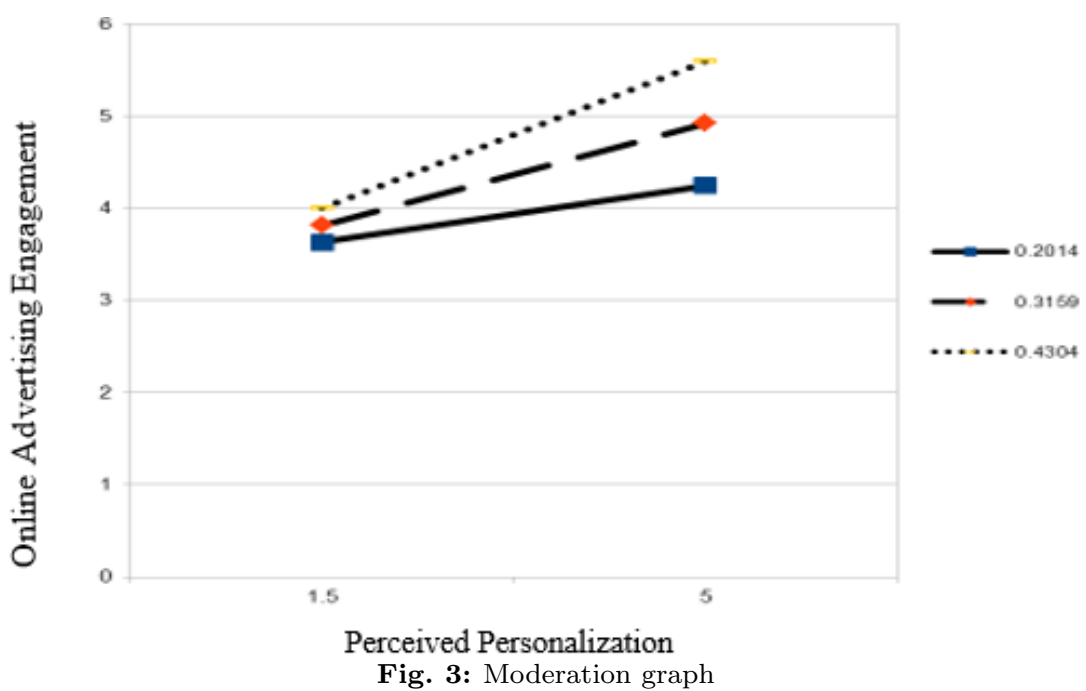

\section{Discussion}

The purpose of the study was to evaluate the cause-and-effect relationship between perceived personalization and online advertising engagement. The potential effect of online privacy concerns was measured on the link between perceived personalization and online advertising engagement. In Hypothesis 1, the perceived personalization effect on online advertising engagement is substantial and positive. Relevant information for a person is cognitively processed and helps to attain objectives (Wilson \& Sperber, 2004). The personalization is being based on the relevant information strategy; therefore it has resulted in an online advertising engagement (Kim and Huh 2017; Calder et al 2009; Wang 2006).

The moderation analysis showed an unanticipated result. One of the likely explanations for this unexpected result could be a conflict between consumers' beliefs about privacy and their online behaviors. They are alarmed about their personal information online, but at the same time, they generally disclose their personal information without any privacy protections in some cases (Ur et al 2012). For example, to get a benefit from the services of social media, or enjoying OBA during online shopping (Phelan et al 2016).

Some studies have even shown that in return for money (McDonald and Cranor 2008) or small benefits (Norberg et al 2007) or free services: reciprocity approach (Schumann et al 2014), people are willing to provide their private information on websites. This is called the paradox of privacy in literature (Norberg et al 2007). This may describe the findings of this study, which is that online users are more conscious about their online privacy, strengthening the relationship between perceived personalization and online advertising engagement. Although they have great concerns about privacy, they engage more with online advertising.

The result of moderation could also be described with the conclusions of

Business Review: (2019) 14(2):31-46 
Lee et al (2015). They took into account the effects of the protection of privacy and the readiness to share information. The results showed that the customer segment most expected to be profitable for e-tailors' personalization strategy presented a high level of privacy concern and a substantial online shopping experience. From these findings, it can logically be determined that the more experienced online users are with the internet shopping, the more they will engage in personalized online advertising. Nonetheless, these results show that this type of engagement does not automatically suggest the loss of privacy and security concerns. These findings also suggest that online retailers should explicitly focus on their privacy policies and security arrangements with their customers, who may be constantly concerned regarding these issues.

In addition to the explanation above, other confounding variables may also affect the outcome of moderation in this study. In spite of a weak connection between perceived personalization and online advertising engagement at the low privacy concerns, it should be strong. The average values of privacy concerns for different age groups indicated that privacy concerns increased with the age of online users. Baek and Morimoto (2012) stated that young people may have fewer privacy concerns than older people. It's because they grew up with online media and are more at ease using it. But still this generation is skeptical about customization/personalization.

Personalization, rather than the protection of privacy, is an underpinning reason for their avoidance of online advertising. Turow et al (2009) mentioned that most adult Americans (66\%) did not want marketers to adapt advertising to their interests. Even among young adults, whom advertisers often consider as less concerned to their personal online information, more than half (55\%) of 18-24 year olds do not want customized advertising. These results corroborate the results of this study, that is, weak privacy concerns weaken the link between perceived personalization and online advertising engagement.

\section{Implications and conclusion}

This study will be useful for understanding the effect of online user privacy issues in Pakistan. Studies in Western countries have already shown that online users are concerned about the privacy of personalized advertising (Lee et al 2015; Phelan et al 2016; Turow et al 2009). People are hesitant about personalized advertisements because they are followed by advertisers based on their personal information. The results of this study exposed the influence of internet privacy concerns on their attitude towards personalized advertising. Therefore, the results of this study will also help online advertisers to send personalized advertisement to suitable segments with respect to privacy issues.

The internet has enticed people of all ages and salary brackets. In Pakistan, even the lower and middle classes have access to its use nowadays. internet is considered vital and its daily use is common (Gallup, 2015). This study delivers Pakistani online advertisers with an initial point which internet users can focus on for personalized advertising. They can further improve personalized engagement approaches for different groups concerned with privacy protection in the 
context of online behavioral advertising with the results of this study in mind.

The findings of the study will be useful not only to local advertisers, but also to international advertisers. Because of the internet, the world has turned into a global village. Advertising a particular product is not limited to a specific area or country. Internet has facilitated access to clients of different cultures and backgrounds (Bleier and Eisenbeiss 2015a). It has increased the trend of online shopping around the world (Mustafa et al 2019). For example, online shopping has made it convenient for anyone from Asia to shop in Western countries. International advertisers can also benefit from the findings of this study. They can personalize the advertisement across different cultures to reduce privacy concerns and boost online shopping internationally.

Furthermore, marketers and online retailers should focus on cultivating engagement strategies. The researchers studied different levels of personalization (Aguirre et al 2015; Bleier and Eisenbeiss 2015a,b). This study assessed the effect of high degree of content personalization (HCP) on online advertising engagement. HCP found to be effective at the initial stage of the buying process, that is, at the stage of collection of information (Bleier and Eisenbeiss 2015b). The present study proves that this level of personalization is able to improve the emotional bond between online users and the brand. So, it is reasonable to say that, in personalized advertising, online retailers can embrace the same level of personalization in their advertisements. This would help them to engage online users in the preliminary phase of the purchasing process. Advertisers need to focus on engagement tactics as an internet user intends to click on online advertising due to the formation of engagement with the brand. Intention further leads to real behavior (Ajzen 1991). A click on the advertisement moves online users to the corresponding website. Once on the website, it is more likely that the purchase intent and actual buying behavior of the online user will develop.

Future studies may investigate the appropriate level of personalization for online users with little privacy concerns in the initial purchase process stage, as the current level of personalized advertisement has not effected them even though the retailer included in this study was one of the most reliable in Pakistan (Christian, 2017). According to (Bleier and Eisenbeiss 2015a), a highly trustworthy retailer and high personalization (depth) can reduce online users' concerns regarding privacy protection. Contrarily, a high degree of personalization and a reliable retailer have not strengthened the relationship between perceived personalization and online advertising engagement. Comparing the average values of different age groups with respect to the protection of privacy (table 6) exposed that the users who are not very concerned about the protection of privacy are for the most part young people. Previous studies have dealt with the unwillingness of younger generations to personalization efforts (Baek and Morimoto 2012; Turow et al 2009). Looking at the literature and results of the current study, it may be wise for advertisers to send low-level, personalized advertisements to young online users.

The results display that the more profitable customers could be those that have high privacy concerns as they get more engaged, thus strengthening the perceived personalization and online advertising engagement relationship. Etailors should take into account the privacy issues of these customers. As the 


\section{U. Noor et al}

attitude of consumers may vary over time, engaging with high-content personalized advertising now, does not guarantee the same response of online consumers in future. Receiving permission from online customers before sending them personalized advertisements and clarifying privacy rules is essential and highly recommended for online advertisers.

Future studies can also extend the model of this study and exploit the intentions and real behaviors of online users. As recommended by Kim et al (2017), advertising engagement literature has been expanded in the social media context. Online advertising engagement has been theorized as an essential outcome of perceived personalization caused by behavioral advertising. In addition, the literature on the protection of privacy has also been explored and expanded. The issue of privacy has been used as a moderator on the relationship between perceived personalization and online advertising engagement. Thus, introducing a new moderator in the key relationship of personalization due to OBA and online advertising engagement presents a theoretical input of this study. Findings of the present study can serve as a base for future research. In particular, consequences of the concern for privacy needs to be explored in different countries.

\section{References}

Aguirre E, Mahr D, Grewal D, de Ruyter K, Wetzels M (2015) Unraveling the personalization paradox: The effect of information collection and trust-building strategies on online advertisement effectiveness. Journal of Retailing 91(1):34-49

Ajzen I (1991) The theory of planned behavior. Organizational behavior and human decision processes 50(2):179-211

Baek TH, Morimoto M (2012) Stay away from me. Journal of advertising 41(1):59-76

Baker WE, Lutz RJ (2000) An empirical test of an updated relevance-accessibility model of advertising effectiveness. Journal of Advertising 29(1):1-14

Berman MG, Jonides J, Lewis RL (2009) In search of decay in verbal short-term memory. Journal of Experimental Psychology: Learning, Memory, and Cognition 35(2):317

Bleier A, Eisenbeiss M (2015a) The importance of trust for personalized online advertising. Journal of Retailing 91(3):390-409

Bleier A, Eisenbeiss M (2015b) Personalized online advertising effectiveness: The interplay of what, when, and where. Marketing Science 34(5):669-688

Boerman SC, Kruikemeier S, Zuiderveen Borgesius FJ (2017) Online behavioral advertising: A literature review and research agenda. Journal of Advertising 46(3):363-376

Calder BJ, Malthouse EC, Schaedel U (2009) An experimental study of the relationship between online engagement and advertising effectiveness. Journal of interactive marketing 23(4):321-331

Celsi RL, Olson JC (1988) The role of involvement in attention and comprehension processes. Journal of consumer research 15(2):210-224

Chaudary S, Rehman MA, Nisar S (2014) Factors influencing the acceptance of online shopping in pakistan

Cho CH (2004) Why do people avoid advertising on the internet? Journal of advertising $33(4): 89-97$

Cui N, Wang T, Xu S (2010) The influence of social presence on consumers perceptions of the interactivity of web sites. Journal of Interactive Advertising 11(1):36-49

Dijkstra A (2004) Working mechanisms of computer-tailored health education: evidence from smoking cessation. Health education research 20(5):527-539

Dolnicar S, Jordaan Y (2007) A market-oriented approach to responsibly managing information privacy concerns in direct marketing. Journal of Advertising 36(2):123-149 
Goldfarb A, Tucker C (2011) Online display advertising: Targeting and obtrusiveness. Marketing Science 30(3):389-404

Hair J, Anderson R, Tatham R, Black W (1998) Multivariate data analysis with readings prentice-hall international inc

Hollebeek L (2011) Exploring customer brand engagement: definition and themes. Journal of strategic Marketing 19(7):555-573

Jacoby J (2002) Stimulus-organism-response reconsidered: an evolutionary step in modeling (consumer) behavior. Journal of consumer psychology 12(1):51-57

Kim H, Huh J (2017) Perceived relevance and privacy concern regarding online behavioral advertising (oba) and their role in consumer responses. Journal of Current Issues \& Research in Advertising 38(1):92-105

Kim J, Ahn SJG, Kwon ES, Reid LN (2017) Tv advertising engagement as a state of immersion and presence. Journal of Business Research 76:67-76

Krejcie RV, Morgan DW (1970) Determining sample size for research activities. Educational and psychological measurement 30(3):607-610

Lee S, Lee Y, Lee JI, Park J (2015) Personalized e-services: consumer privacy concern and information sharing. Social Behavior and Personality: an international journal 43(5):729740

Li C (2016) When does web-based personalization really work? the distinction between actual personalization and perceived personalization. Computers in human behavior 54:25-33

Li H, Edwards SM, Lee JH (2002) Measuring the intrusiveness of advertisements: Scale development and validation. Journal of advertising 31(2):37-47

McDonald AM, Cranor LF (2008) The cost of reading privacy policies. Isjlp 4:543

Mustafa MB, Nafees M, Aftab S (2019) Why not with the flow? a case of online shoppers in pakistan toward online shopping. In: Conference Book, p 52

Norberg PA, Horne DR, Horne DA (2007) The privacy paradox: Personal information disclosure intentions versus behaviors. Journal of consumer affairs 41(1):100-126

Nowak GJ, Phelps JE (1992) Understanding privacy concerns: an assessment of consumers information-related knowledge and beliefs. Journal of Direct Marketing 6(4):28-39

Pavlou PA, Stewart DW (2000) Measuring the effects and effectiveness of interactive advertising: A research agenda. Journal of Interactive Advertising 1(1):61-77

Phelan C, Lampe C, Resnick P (2016) It's creepy, but it doesn't bother me. In: Proceedings of the $2016 \mathrm{CHI}$ conference on human factors in computing systems, ACM, pp 5240-5251

Phelps J, Nowak G, Ferrell E (2000) Privacy concerns and consumer willingness to provide personal information. Journal of Public Policy \& Marketing 19(1):27-41

Rappaport SD (2007) Lessons from online practice: new advertising models. Journal of Advertising Research 47(2):135-141

Robinson H, Wysocka A, Hand C (2007) Internet advertising effectiveness: the effect of design on click-through rates for banner ads. International Journal of Advertising 26(4):527-541

Schumann JH, von Wangenheim F, Groene N (2014) Targeted online advertising: Using reciprocity appeals to increase acceptance among users of free web services. Journal of Marketing 78(1):59-75

Sheehan KB, Hoy MG (1999) Flaming, complaining, abstaining: How online users respond to privacy concerns. Journal of advertising 28(3):37-51

Sherman L, Deighton J (2001) Banner advertising: Measuring effectiveness and optimizing placement. Journal of Interactive Marketing 15(2):60-64

Smith HJ, Milberg SJ, Burke SJ (1996) Information privacy: measuring individuals' concerns about organizational practices. MIS quarterly pp 167-196

Stanaland AJ, Lwin MO, Miyazaki AD (2011) Online privacy trustmarks: Enhancing the perceived ethics of digital advertising. Journal of Advertising Research 51(3):511-523

Tam KY, Ho SY (2006) Understanding the impact of web personalization on user information processing and decision outcomes. MIS quarterly pp 865-890

Tucker CE (2014) Social networks, personalized advertising, and privacy controls. Journal of Marketing Research 51(5):546-562

Turow J, King J, Hoofnagle CJ, Bleakley A, Hennessy M (2009) Americans reject tailored advertising and three activities that enable it. Available at SSRN 1478214

Ur B, Leon PG, Cranor LF, Shay R, Wang Y (2012) Smart, useful, scary, creepy: perceptions of online behavioral advertising. In: proceedings of the eighth symposium on usable privacy and security, ACM, p 4

Business Review: (2019) 14(2):31-46 
Van Doorn J, Lemon KN, Mittal V, Nass S, Pick D, Pirner P, Verhoef PC (2010) Customer engagement behavior: Theoretical foundations and research directions. Journal of service research 13(3):253-266

Van Noort G, Smit EG, Voorveld HA (2013) The online behavioural advertising icon: two user studies. In: Advances in Advertising Research (Vol. IV), Springer, pp 365-378

Vivek SD, et al (2009) A scale of consumer engagement. PhD thesis, University of Alabama Libraries

Wang A (2006) Advertising engagement: A driver of message involvement on message effects. Journal of Advertising Research 46(4):355-368

Wasserman T (2013) This is the world's first banner ad. Mashable Mashable 9

Westin AF (1967) Privacy and freedom atheneum. New York 7:431-453

White TB, Zahay DL, Thorbjørnsen H, Shavitt S (2008) Getting too personal: Reactance to highly personalized email solicitations. Marketing Letters 19(1):39-50 